\title{
Correction to: Effects of Lactogen 13, a New Probiotic Preparation, on Gut Microbiota and Endocrine Signals Controlling Growth and Appetite of Oreochromis niloticus Juveniles
}

\author{
Giorgia Gioacchini ${ }^{1}$ - Elia Ciani ${ }^{1}$ - Andrea Pessina ${ }^{1}$ - Cinzia Cecchini ${ }^{1}$ - Stefania Silvi ${ }^{2}$. Ana Rodiles ${ }^{3}$. \\ Daniel L. Merrifield ${ }^{3} \cdot$ Ike Olivotto $^{1} \cdot$ Oliana Carnevali $^{1}$
}

Published online: 23 April 2018

(C) Springer Science+Business Media, LLC, part of Springer Nature 2018

Correction to: Microbial Ecology

https://doi.org/10.1007/s00248-018-1177-1

The original version of this article unfortunately contained mistakes in Authors First name/Family name order.

The correct version is presented above.

The online version of the original article can be found at https://oi.org/ 10.1007/s00248-018-1177-1

Oliana Carnevali

o.carnevali@univpm.it

1 Dipartimento di Scienze della Vita e dell'Ambiente, Università Politecnica delle Marche, Via Brecce Bianche, 60131 Ancona, Italy

2 Scuola di Bioscienze e Medicina Veterinaria, Università degli Studi di Camerino, Camerino, Italy

3 Aquatic Animal Nutrition and Health Research Group, School of Biological and Marine Sciences, Plymouth University,

Plymouth PL4 8AA, UK 